\title{
Exploration and Research on HIV/AIDS Patients' Complement C1q Level Changes before and after Treatments
}

\author{
Guosheng Su${ }^{1,2,3}$, Xiaolu Luo ${ }^{1,2,3 *}$, Shunda Luo ${ }^{1,2,3}$, Zeduan Liu' ${ }^{1,2,3}$, Zuyan Ni 1,2,3, \\ Wanhong Huang1,2,3, Juanying Liang 1,2,3 \\ ${ }^{1}$ The Fourth People's Hospital Clinical Laboratory, Nanning, China \\ ${ }^{2}$ Guangxi Medical University Hospital for Infectious Diseases, Nanjing, China \\ ${ }^{3}$ Guangxi AIDS Clinical Treatment Center, Nanning, China \\ Email: suguoshengv@sina.com, ${ }^{*}$ luoxiaolu2007@126.com, 405386593@qq.com, 1220377608@qq.com, \\ 416614591@qq.com, asjbwan@sina.com, 1263050345@qq.com
}

Received 26 July 2015; accepted 21 September 2015; published 24 September 2015

Copyright (C) 2015 by authors and Scientific Research Publishing Inc.

This work is licensed under the Creative Commons Attribution International License (CC BY). http://creativecommons.org/licenses/by/4.0/

(c) (i) Open Access

\begin{abstract}
Objective: The study aimed to investigate the complement C1q test results of HIV/AIDS patients in clinical application before and after treatments. Methods: We collected HIV/AIDS patients' serum specimens storing at $\mathbf{- 8 0}$ centigrade freezer in cryogenic refrigerator for standby. After samples quantity met the requirements of selected cases unified, complement C1q was detected by immune transmission turbidity method, and compared the differences in complement C1q of HIV/AIDS patients in test results before and after treatment. In the collection of 96 cases selected samples, concentration of complement C1q was $157.95 \pm 31.46 \mathrm{mg} / \mathrm{L}$ before treatment, while after treatment, it was $147.26 \pm 28.76 \mathrm{mg} / \mathrm{L}$. Comparing the results before and after treatment, $t=$ 2.45726, $P=0.01049$, the difference was statistically significant. Concentration of complement C1q increased after treatment with 33 cases. There were 63 cases reducing. Through statistical analysis on the data from the number of reducing and increasing cases, chi-square $=18.75, P=$ 0.00356, the difference was statistically significant. Complement C1q detection in the treatment of patients with HIV/AIDS had an important clinical significance in the process. The analysis of the concentration changes before and after treatment was clinically significant for drug selection and monitoring disease progression and curative effects, which would be worth further researching.
\end{abstract}

\section{Keywords}

HIV, AIDS, Complement C1q, Immune Transmission Turbidity

"Corresponding author.

How to cite this paper: Su, G.S., Luo, X.L., Luo, S.D., Liu, Z.D., Ni, Z.Y., Huang, W.H. and Liang, J.Y. (2015) Exploration and Research on HIV/AIDS Patients' Complement C1q Level Changes before and after Treatments. Advances in Infectious Diseases, 5, 114-117. http://dx.doi.org/10.4236/aid.2015.53013 


\section{Introduction}

The changes of serum complement $\mathrm{C} 1 \mathrm{q}$ concentration mainly reflect nephropathy immune complex diseases, such as lupus nephritis, rheumatoid arthritis, glomerulonephritis, etc. The complement C1q concentration levels decrease when kidney disease and immune complex disease is in the acute and active stage. While it's in the remission and recovery stage, complement C1q concentration levels become high [1]-[3]. HIV/AIDS being kind of immunodeficiency disease, is there any change of complement C1q concentration levels before and after treatment and does this change will guide the treatment of patients with HIV/AIDS? As for this, there isn't related research and news at home and abroad. This study obtains certain achievements, now I'll show the results as follows.

\section{Materials and Methods}

\subsection{Objects of Study}

We selected 96 patients with HIV/AIDS in Guangxi AIDS patients clinical treatment center from September to July in 2011. Among those objectives, there were 69 and 27 cases of male and female separately, whose ages are between 22 to 82 . The average age is 41.87 , more or less 1.372 years old. Objectives who saw doctors for the first time without any treatment and they had a second examination after six months treatment.

\subsection{Research Methods}

Limos is vein blood sample of $3 \mathrm{ml}$ were collected from cases before and after treatment. After separated, they were stored at -80 centigrade freezer in cryogenic refrigerator for standby. As soon as the samples quantity met the requirements of selected cases unified, complement C1q was detected by immune transmission turbidity method, and compared the differences in complement C1q of HIV/AIDS patients in test results before and after treatment.

\subsection{Remarks}

This study obtained support and approval from Guangxi Association of STD and AIDS prevention (NO. 49852135-5). During this research, we protected patients' privacy. If not, the related research studies were approved by Guangxi Association of STD and AIDS prevention and those patients' approval.

\subsection{Instrumentation and Reagents}

Instrumentation: Automatic biochemical analyzer is Germany Roche PPE800. Reagents: complement C1q detection kits were provided by Shanghai Beijia Biochemical Reagent Co., Ltd. Reagent lot is 14021201 and production date is February 12, 2014. They remain valid until February 11, 2015.

\subsection{Reference Interval}

It's between $159 \mathrm{mg} / \mathrm{L} \sim 233 \mathrm{mg} / \mathrm{L}$.

\subsection{Control of Quality}

The calibration is required in each test and it needed to be re-scaled in different reagent lots. Before testing, we carried out quality control every day. If it passed the requirement of quality control, the samples could be tested. According to the requirement of instrumentation, reagent and sample consumption may be changed in proportion.

In order to avoid repeating to pour reagents in and out container, we used them according to their actual dosage levels. Screw the cover tightly for preservation in refrigerator after use.

\subsection{Statistical Treatment}

Statistic process software Graph Pad Prism 5.0 was used to analyze statistically. The comparison of technical data was tested by chi-square. Data are analyzed by $t$ inspection and $\chi^{2}$ inspection and results showed with the 
average $\mathrm{X} \pm \mathrm{S}$. Take $P<0.05$ as the statistically significant difference.

\section{Results}

Among those 96 cases, complement C1q concentration was $157.95 \pm 31.46 \mathrm{mg} / \mathrm{L}$ before treatment, while after treatment, it was $147.26 \pm 28.76 \mathrm{mg} / \mathrm{L}$. Compared with before and after treatments, $t=2.45726, P=0.01049$, it had significant difference. The complement C1q concentration with 33 cases increased after treatment. Before and after treatment, the average concentrations were $140.39 \pm 5.085,169.97 \pm 4.79$ separately. Compared with pre-post treatment, $t=24.3242, P=0.00106$. After treatment, the complement C1q concentration is constant with one cases and with 62 cases were unchangeable. Before and after treatment, the average concentrations were 167.14 $\pm 2.68,135.37 \pm 3.60$. Compared with pre-post treatment, $t=56.1865, P=0.000459$. Comparison with cases of increased and reduced, the difference is statistically significant, $\chi^{2}=18.75, P=0.00356$. For further details, please look at Table 1.

\section{Discussion}

Clq is an important complement system which can identify molecular start classical pathway, and in specific immunity and innate immunity, it plays a connecting role [1]. Complement C1q detection is considered to have an important clinical application in kidney disease. When the complement $\mathrm{C} 1 \mathrm{q}$ participation and the occurrence of nephritis, disease activity on the serum C1q concentration significantly decrease in the remission stage, while the complement C1q does not participate in the nephritis patients, the serum C1q concentration is significantly higher than that of complement $\mathrm{C} 1 \mathrm{q}$ involved in glomerulonephritis patients. In classic activation way, complement C1q can have great effect on initial recognition. The test items complement C1q can observe the activation state of the classical pathway to identify the activation defects of the complement system in the classical pathway and alternative pathway. Activation of the complement can combine with immune complex in antigen antibody (IgG, IgM) of the FC binding. Result in immune complex formation is reserved in local tissue of the human body and causing local tissue inflammatory immune response, such as joint swelling, lupus nephritis and glomerulonephritis [4] [5]. Serum complement C1q can diagnose congenital complement C1q disease, which represents mixed immune deficiency, systemic lupus erythematosus and glomerulonephritis, etc. [6] [7]. As an immunodeficiency disease, to explore whether there are certain differences before and after the anti-re-troviral treatment of serum complement $\mathrm{C} 1 \mathrm{q}$ is worth of further exploration and research.

According to the results of this study, there is obvious difference of serum complement C1q in patients with HIV/AIDS antiretroviral treatment. The observation of overall cases, the majority of patients serum complements C1q level reduce, and a small number of cases increase. While, only one case is unchangeable. Compared with serum C1q concentration decreased or unchanged number of patients and the number of patients rose in the concentration, chi-square $=18.75, P=0.00356$. The difference is statistically significant. Before treatment, kidney function is undamaged. The level of serum complement C1q concentration is on the basic state. After antiretroviral therapy, the side effects of antiviral drugs cause kidney damage, which belongs to disease activity. Complement C1q is involved in activation of renal damage in patients with HIV/AIDS, the serum complement C1q concentration level reduced, while the level of complement C1q was not involved in the renal injury patients activation, those patients' serum C1q concentration increased or unchanged. while the level of complement

Table 1. Before and after treatment in patients with HIV/AIDS complement C1q the comparison of test results.

\begin{tabular}{|c|c|c|c|c|c|c|}
\hline \multirow{2}{*}{ group } & \multicolumn{2}{|c|}{ Treatment observation cases } & \multicolumn{2}{|c|}{$\begin{array}{l}\text { Concentration increases the } \\
\text { number of cases after treatment }\end{array}$} & \multicolumn{2}{|c|}{$\begin{array}{l}\text { Concentration unchanged or reduce } \\
\text { the number of cases after treatment }\end{array}$} \\
\hline & $\begin{array}{l}\text { The number } \\
\text { of cases }\end{array}$ & $\begin{array}{l}\text { The mean } \\
\text { concentration }(\mathrm{mg} / \mathrm{L})\end{array}$ & $\begin{array}{l}\text { The number } \\
\text { of cases }\end{array}$ & $\begin{array}{l}\text { The mean } \\
\text { concentrations }(\mathrm{mg} / \mathrm{L})\end{array}$ & $\begin{array}{l}\text { The number } \\
\text { of cases }\end{array}$ & $\begin{array}{l}\text { The mean } \\
\text { concentrations }(\mathrm{mg} / \mathrm{L})\end{array}$ \\
\hline $\begin{array}{l}\text { Before the } \\
\text { treatment }\end{array}$ & 96 & $157.95 \pm 31.46$ & 33 & $140.39 \pm 5.085$ & 63 & $167.14 \pm 3.60$ \\
\hline After treatment & 96 & $147.26 \pm 28.76$ & 33 & $169.97 \pm 4.79$ & 63 & $135.37 \pm 2.68$ \\
\hline$T$ value & - & 2.45726 & - & 24.3242 & - & 56.1865 \\
\hline$P$ values & - & 0.01049 & - & 0.00106 & - & 0.000459 \\
\hline
\end{tabular}


C1q was not involved in the renal injury patients activation, those patients' serum C1q concentration increased or unchanged. The foundation of this will identify patients complement C1q defects, which are beneficial to patients with HIV/AIDS to observe the laboratory differential diagnosis, prognosis and treatment effect.

After careful experiments and analysis, this study find that serum complement C1q detection After careful experiments and analysis, this study found that serum complement C1q detection not only plays a good assessment role in kidney disease and have good effects in kidney disease and the aspect of HIV/AIDS patients laboratory diagnosis, but also can be used as laboratory diagnosis of HIV/AIDS patients, observation and prognostic evaluation and treatment of a good indicator, which are worthy of popularization and application.

\section{Contributions}

Guosheng Su is responsible for the total project organization coordinated implementation. Xiaolu Luo and Shunda Luo participated in research. Zeduan Liu and Zuyan Ni were responsible for case collection and data statistics. Wanhong Huang and Juanying Liang were responsible for clinical detection and data processing.

\section{Acknowledgements}

During this topic research process, we got much help from many departments and individuals, and other personnel not involved in this project research, all of them offered a great support and help in this research. Now here, all of members of this research group show our deepest appreciation to them, and wish them good health and everything goes well.

\section{Funding}

The funding of this study are Guangxi Nanning City Science and Technology Plan Projects of the People's Republic of China (NO. 20123164). The Guangxi Zhuang Autonomous Region health department self-financing scientific research project (NO. Z2012621).

\section{Declaration}

The authors declare that they have no competing interests.

\section{References}

[1] Ding, R.R. and Xing, G.Q. (2014) IgA Nephropathy Patients Complement Classic Way in Blood and Urine Activation and Its Relationship with Renal Damage. Journal of Clinical Microbiology, 31, 186-188.

[2] Liu, G., Feng, Y., Liu, X., et al. (2013) C1q Structure, Distribution, Classification and Function of Protein Family. Journal of Heredity, 35, 1072-1080.

[3] Liao, J.L., Zheng, A.P., Jiang, L., et al. (2013) Antibodies against C1q and Kidney Pathology Relations with Lupus Nephritis. Journal of Clinical and Experimental Pathology, 29, 155-158.

[4] Feng, X.B., Ke, J.J. and Rao, Y., et al. (2014) Effect of Complement C1q Expression on Hepatic Ischemia-Reperfusion Injury in Rats. J HuazhongUnivSci Technol [MedSci], 34, 403-407.

[5] Son, M., Santiago-Schwarz, F., AI-Abed, Y., et al. (2012) Clq Limits Dendritic Cell Differentiation and Activation by Engaging LAIR-1. Proceedings of the National Academy of Sciences of the United States of America, 109, E3160E3167. http://dx.doi.org/10.1073/pnas.1212753109

[6] Xu, F.F., Bu, X.M., Li, W., et al. (2013) C1q Deposition of V-Shaped with Lupus Nephritis and the Differential Diagnosis of Primary Membranous Nephropathy Significance. Chinese Journal of Traditional Chinese and Western Medicine Combined with Kidney Disease, 14, 317-319.

[7] Hu, X.P., Liu, R.H. and Chen, J. (2014) The Test Level of C3, C4 and C1q on Judgment with Lupus Nephritis Activity of Value. Journal of Guiyang Medical College, 33, 191-193. 